\title{
Short-term exposure to air pollution and hospital admission for pneumonia: a systematic review and meta-analysis
}

\author{
Jeong Yee ${ }^{1 \dagger}$, Young Ah Cho ${ }^{2,3 \dagger}$, Hee Jeong Yoo ${ }^{1,4}$, Hyunseo Yun ${ }^{5}$ and Hye Sun Gwak ${ }^{1 *}$ (D)
}

\begin{abstract}
Background: Air pollution is a major issue that poses a health threat worldwide. Although several studies investigated the adverse effects of air pollution on various diseases, few have directly demonstrated the effects on pneumonia. Therefore, we performed a systematic review and meta-analysis on the associations between shortterm exposure of air pollutants and hospital admission or emergency room (ER) visit for pneumonia.

Methods: A literature search was performed using PubMed, Embase, and Web of Science up to April 10, 2020. Pooled estimates were calculated as \% increase with 95\% confidence intervals using a random-effects model. A sensitivity analysis using the leave-one-out method and subgroup analysis by region were performed.

Results: A total of 21 studies were included in the analysis. Every $10 \mu \mathrm{g} / \mathrm{m}^{3}$ increment in $\mathrm{PM}_{2.5}$ and $\mathrm{PM}_{10}$ resulted in a 1.0\% (95\% Cl: $0.5-1.5)$ and $0.4 \%$ (95\% Cl: 0.2-0.6) increase in hospital admission or ER visit for pneumonia, respectively. Every $1 \mathrm{ppm}$ increase of $\mathrm{CO}$ and $10 \mathrm{ppb}$ increase of $\mathrm{NO}_{2}, \mathrm{SO}_{2}$, and $\mathrm{O}_{3}$ was associated with $4.2 \%$ (95\% Cl: $0.6-7.9), 3.2 \%$ (95\% Cl: 1.3-5.1), 2.4\% (95\% Cl: - 2.0-7.1), and 0.4\% (95\% Cl: 0-0.8) increase in pneumonia-specific hospital admission or ER visit, respectively. Except for $\mathrm{CO}$, the sensitivity analyses yielded similar results, demonstrating the robustness of the results. In a subgroup analysis by region, $\mathrm{PM}_{2.5}$ increased hospital admission or ER visit for pneumonia in East Asia but not in North America.

Conclusion: By combining the inconsistent findings of several studies, this study revealed the associations between short-term exposure of air pollutants and pneumonia-specific hospital admission or ER visit, especially for PM and $\mathrm{NO}_{2}$. Based on the results, stricter intervention policies regarding air pollution and programs for protecting human respiratory health should be implemented.
\end{abstract}

Keywords: Air pollutants, Particulate matter, Pneumonia, Systematic-review, Meta-analysis

\section{Background}

Pneumonia is a common but potentially life-threatening disease with a high incidence around the world [1]. It is considered a leading infectious cause of hospitalization and death with rising health care costs [2]. The annual

\footnotetext{
* Correspondence: hsgwak@ewha.ac.kr

†Jeong Yee and Young Ah Cho contributed equally to this work.

'College of Pharmacy and Graduate School of Pharmaceutical Sciences,

Ewha Womans University, 52 Ewhayeodae-gil, Seodaemun-gu, Seoul 03760, Republic of Korea

Full list of author information is available at the end of the article
}

incidence of pneumonia is around 2.5 cases per 1000 adults with almost $20 \%$ requiring intensive care and $2 \%$ deaths. In terms of management, the cost of inpatient care is 25 times that of outpatient care [3].

Air pollution still poses a major health threat worldwide. It has been reported that over $90 \%$ of the world's population live in areas where the air pollution level exceeds the World Health Organization (WHO) guideline limits [4]. Air pollution has raised serious concerns regarding environment and public health [5]. According to

(c) The Author(s). 2021 Open Access This article is licensed under a Creative Commons Attribution 4.0 International License, which permits use, sharing, adaptation, distribution and reproduction in any medium or format, as long as you give appropriate credit to the original author(s) and the source, provide a link to the Creative Commons licence, and indicate if changes were made. The images or other third party material in this article are included in the article's Creative Commons licence, unless indicated otherwise in a credit line to the material. If material is not included in the article's Creative Commons licence and your intended use is not permitted by statutory regulation or exceeds the permitted use, you will need to obtain permission directly from the copyright holder. To view a copy of this licence, visit http://creativecommons.org/licenses/by/4.0/ The Creative Commons Public Domain Dedication waiver (http://creativecommons.org/publicdomain/zero/1.0/) applies to the data made available in this article, unless otherwise stated in a credit line to the data. 
WHO, ambient air pollution accounted for 4.2 million deaths in 2016, which represented $7.6 \%$ of all deaths worldwide [4]. The adverse effects of air pollution have been investigated on various diseases [6-8].

The air pollution can increase the onset risk of pneumonia, including both hospitalization $[9,10]$ and outpatient visit [11]. In addition, particulate matter (PM) can worsen the prognosis of pneumonia patients; according to Chen et al. [12], it was associated with increased risk of invasive respiratory and/or vasopressor support and in-hospital mortality.

Although several studies systemically reviewed the effects of particulate matter (PM) on hospital admissions for respiratory diseases, such as asthma and chronic obstructive pulmonary disease (COPD) [13, 14], few have directly investigated the effects of air pollutants on pneumonia-specific hospital admission or emergency room (ER) visit. To summarize the existing evidence and provide a quantitative answer to the above concerns, we performed a systematic review and meta-analysis for the association between short-term exposure of air pollutants and hospital admission or ER visit for pneumonia.

\section{Methods}

\section{Literature search strategy}

The literature search was performed using PubMed, Embase, and Web of Science for studies on the association between short-term exposure to air pollution and hospital admission or ER visit for pneumonia up to April 10, 2020. The search included keywords related to air pollution $\left(\mathrm{PM}_{2.5}, \mathrm{PM}_{10}, \mathrm{SO}_{2}, \mathrm{NO}_{2}, \mathrm{CO}\right.$, and $\left.\mathrm{O}_{3}\right)$ and hospital admission or ER visit for pneumonia. The search strategy is detailed in Supplementary Table 1, Additional file 1. After removing duplicates, two researchers independently screened the titles and abstracts of all records to identify potentially eligible studies. Then, a full-text review was performed to determine the final inclusion according to eligibility criteria. In cases of disagreement, a consensus was reached by discussion.

\section{Inclusion and exclusion criteria}

Studies were included if they: (1) were original studies published in peer-reviewed journals, (2) investigated the short-term effects (defined as those occurring up to 5 days prior to the hospital admission or ER visit) of air pollutants on hospital admission or ER visit for pneumonia, (3) provided sufficient information to calculate regression estimates and 95\% confidence intervals (CIs),

(4) used time-series or case-crossover study design, and

(5) were published in English. Exclusion criteria were:

(1) reviews, commentaries, or editorials; (2) in vitro or in vivo studies; (3) studies on children only; (4) studies under special conditions (e.g., high and low temperature) without overall estimates; or (5) studies on combined outcomes with other respiratory diseases. If there were overlapping data, only the most recent and comprehensive data were included in the meta-analysis.

\section{Data extraction}

Data were extracted independently by two researchers and discrepancies were resolved by consensus. The following information was extracted from each study: name of the first author, publication year, study setting, study design, number of cases, percentages of male and elderly patients, air pollutants studied, outcome level, and study results. If there were multiple lag estimates for the same exposure, only one estimate was selected to prevent over-representation of a single study in the metaanalysis. For multiple lag estimates, a priori lag selection protocol devised by Atkinson et al. was used with the following priorities: (1) the lag that the author focused on in the abstract or stated a priori, (2) the lag with the most statistical significance (positive or negative), and (3) the lag that showed the largest effect estimate (positive or negative) [15].

\section{Quality assessment}

Due to the lack of validated scales for quality assessment of time-series and case-crossover studies, we adapted the quality assessment approach developed by Mustafic et al. [16]. Three components were assessed: (1) pneumonia diagnosis, where one point was given if the diagnosis of pneumonia was coded according to the International Classification of Diseases (ICD) or based on medical records; (2) the air pollutant measures, where one point was given if measurements were performed at least daily with less than $25 \%$ missing data; (3) adjustment for confounders, where one point was given if an adjustment for either long-term trends, seasonality, or temperature was made; a second point was given if an additional adjustment was performed either for humidity or day of the week; and a third point was given if a further adjustment was made for influenza epidemics or holidays. Studies that achieved maximum points for all three components were regarded as good quality, whereas those that achieved no points in any of the three components were regarded as low quality; the remaining were regarded as intermediate quality.

\section{Statistical analysis}

We used \% increase with 95\% CIs as a measure of effect size. To pool the results, all estimates were standardized to an increase of $10 \mu \mathrm{g} / \mathrm{m}^{3}$ of $\mathrm{PM}_{2.5}$ and $\mathrm{PM}_{10}$ concentrations; $1 \mathrm{ppm}$ of $\mathrm{CO} ; 10 \mathrm{ppb}$ of $\mathrm{SO}_{2}, \mathrm{NO}_{2}$, and $\mathrm{O}_{3}$. To transform the estimate, the following equation was used: odds ratio $(\mathrm{OR})_{\text {standardized }}=\mathrm{OR}^{\text {increment(10)/increment(original) }}$ [17]. As the authors of the original articles adjusted for the time-varying confounders, we extracted the adjusted 
values. Statistical significance was analyzed by Z-test and a $p$-value $<0.05$ was considered statistically significant. Heterogeneity between studies was assessed by a chi square-based $\mathrm{Q}$ test and $\mathrm{I}^{2}$ test. A randomeffects model (DerSimonian-Laird method) was applied to consider the heterogeneity within and between studies and to give a more conservative estimate of statistical confidence [18]. Publication bias was assessed using funnel plot and Begg's test [19]. Sensitivity analysis using the leave-one-out method was performed to assess the stability of results. Subgroup analysis was also conducted per region. In addition, meta-analyses for combining the results with the same lag day were performed. All statistical analyses were performed using $\mathrm{R}$ software (version 3.6.0; $\mathrm{R}$ Foundation for Statistical Computing, Vienna, Austria). This review followed the Preferred Reporting Items for Systematic Reviews and Meta-analysis (PRIS MA) guidelines [20].

\section{Results}

The study selection process is summarized in Fig. 1. A total of 1334 records were identified from the three databases and 396 duplicates were excluded. After removing 835 studies during title and abstract screening, 103 were selected for full-text review, and 82 studies were excluded for the following reasons: reviews or letter $(n=$ $4)$, different outcomes $(n=3)$, combined outcomes $(n=$ $31)$, irrelevant studies $(n=10)$, not providing short-term effects $(n=3)$, not providing overall effects $(n=10)$, conducted in children $(n=1)$, unable to extract data $(n=1)$, and overlapping studies $(n=19)$. Finally, 21 studies were included for meta-analysis [9, 10, 21-39].

The characteristics of included studies are shown in Table 1 . Of the 21 remaining studies, 14 were timeseries studies and 7 were case-crossover studies. The United States of America was the country where the research was most conducted $(n=7)$, followed by China $(n=4)$. Most studies used the ICD code for pneumonia diagnosis; almost $60 \%$ of the studies examined hospital admission, while the rest examined ER visit. The number of cases in each study ranged from 325 to 4.2 million. In terms of study quality, about $43 \%$ of studies were regarded as good quality, while the rest were intermediate quality.

Among the air pollutants analyzed, $\mathrm{PM}_{2.5}, \mathrm{PM}_{10}, \mathrm{NO}_{2}$, and $\mathrm{CO}$ were associated with an increased risk of hospital admission or ER visit for pneumonia (Fig. 2). For $\mathrm{PM}_{2.5}$ and $\mathrm{PM}_{10}$, a $10 \mu \mathrm{g} / \mathrm{m}^{3}$ increase was associated with a $1.0 \%\left(95 \%\right.$ CI: $\left.0.5-1.5 ; \mathrm{I}^{2}=70 \%\right)$ and $0.4 \%(95 \%$ CI: $0.2-0.6 ; \mathrm{I}^{2}=49 \%$ ) increase in hospital admission or ER visit for pneumonia, respectively. In addition, every 1 ppm increase of $\mathrm{CO}$ was associated with $4.2 \%$ (95\% CI: 0.6-7.9; $\mathrm{I}^{2}=85 \%$ ) increase in hospital admission or ER visit for pneumonia. For every $10 \mathrm{ppb}$ increase of $\mathrm{NO}_{2}$, $\mathrm{SO}_{2}$, and $\mathrm{O}_{3}$ increased pneumonia-specific hospital admission or ER visit by $3.2 \%$ (95\% CI: $1.3-5.1 ; \mathrm{I}^{2}=60 \%$ ), 2.4\% (95\% CI: $-2.0-7.1 ; \mathrm{I}^{2}=75 \%$ ), and $0.4 \%$ (95\% CI: $0-$ $\left.0.8 ; \mathrm{I}^{2}=48 \%\right)$, respectively.

The publication bias was assessed using the funnel plot and Begg's test (See Supplementary Figure 1, Additional file 1) and no evidence of publication bias was found ( $P>0.05$ for all analyses). Sensitivity analysis was

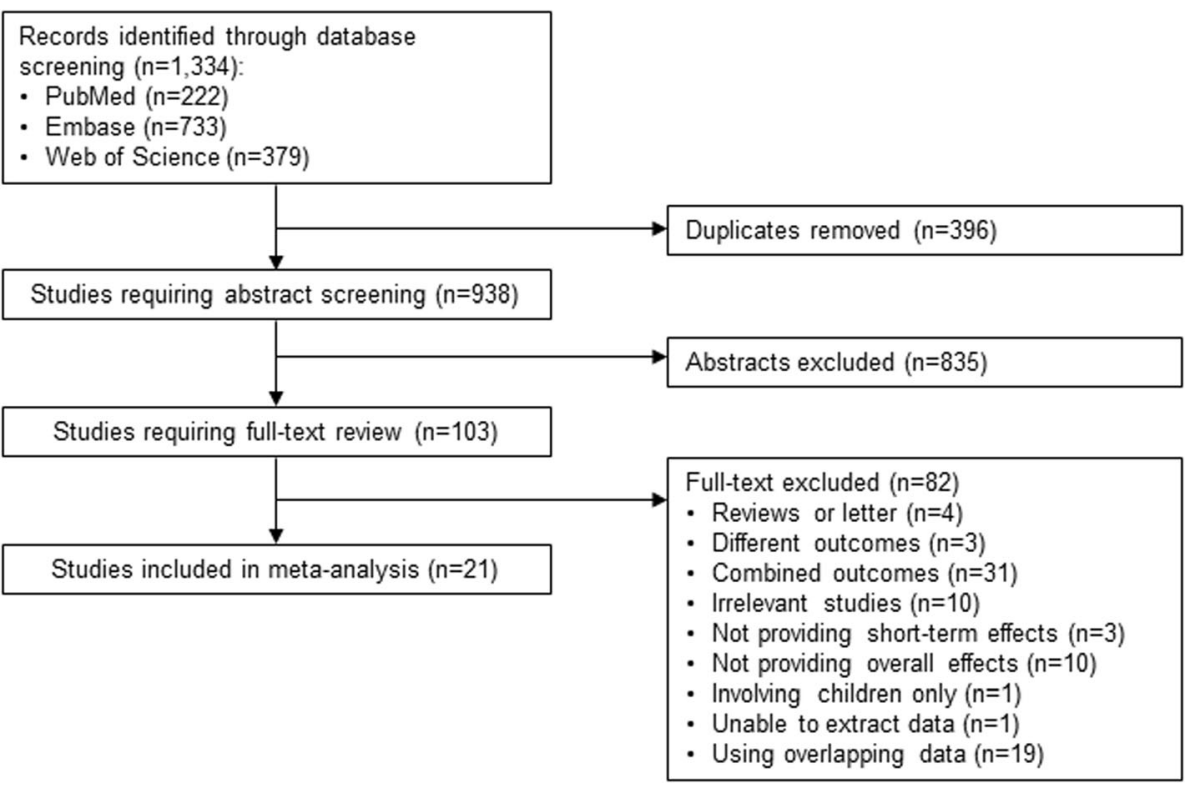

Fig. 1 Flow diagram of study selection 


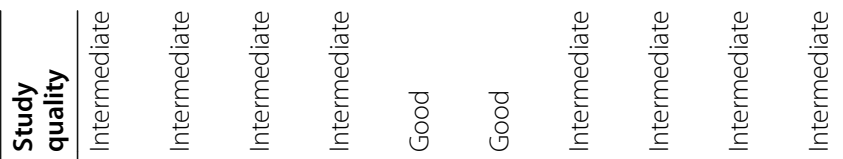

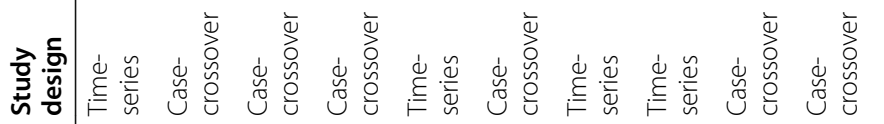

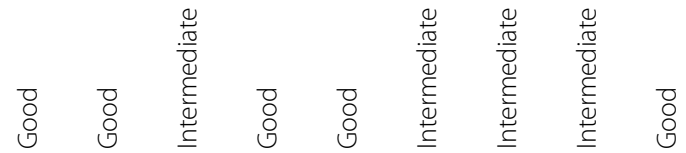

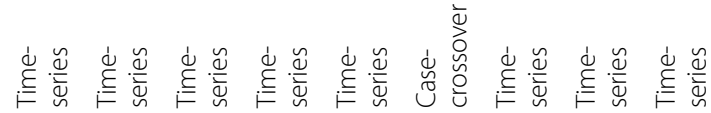

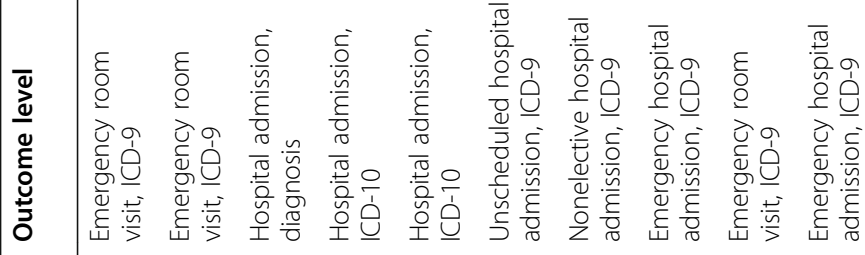

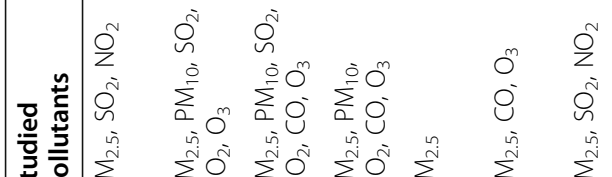

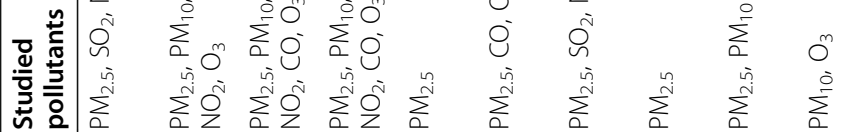

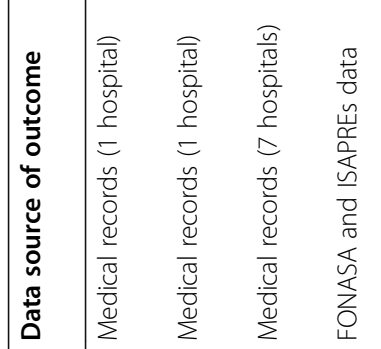

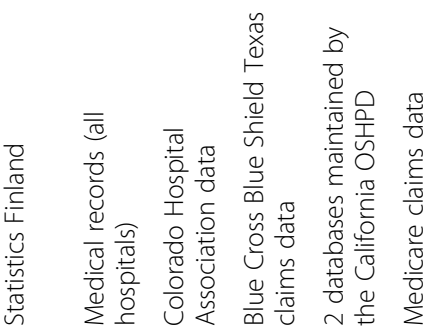

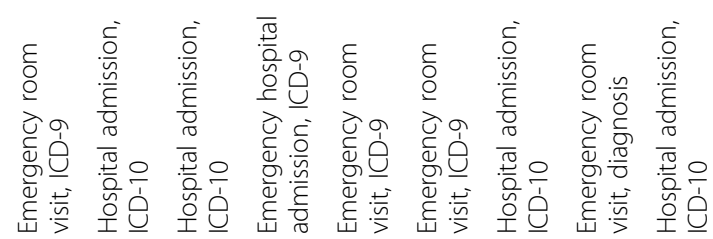

空

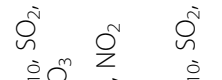

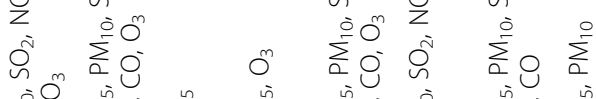

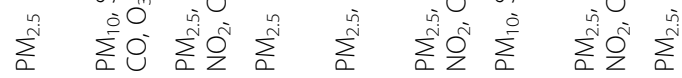

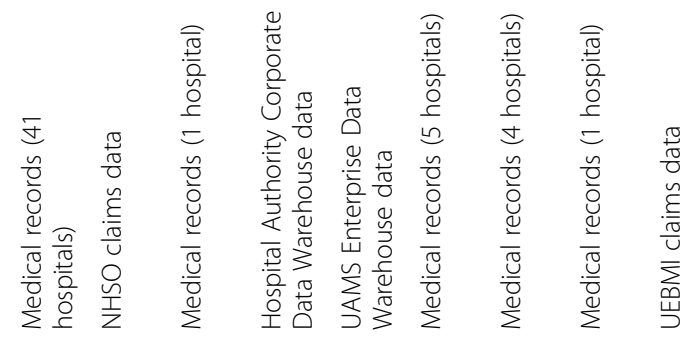

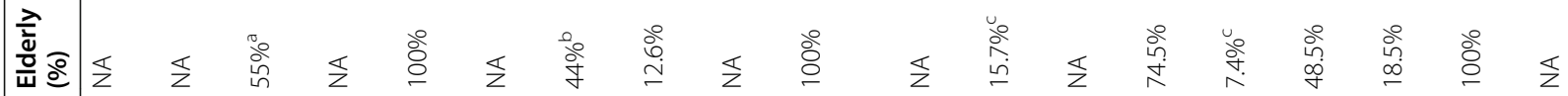

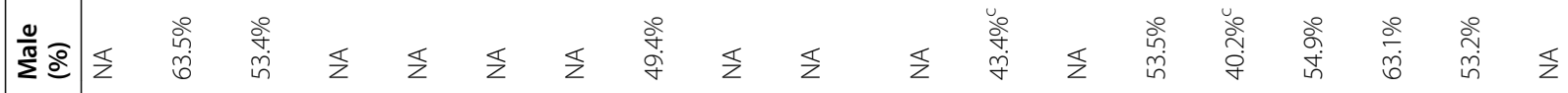

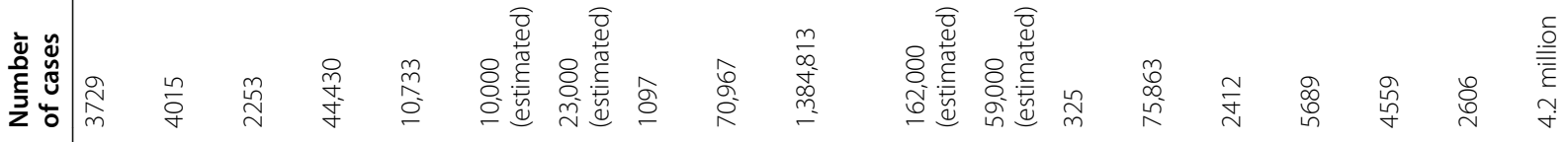

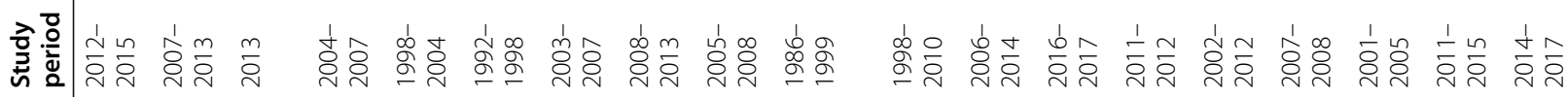

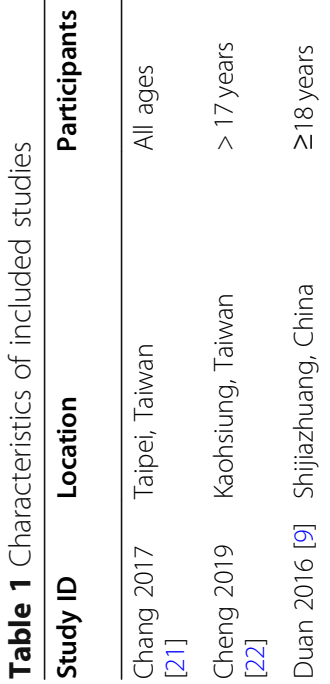

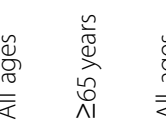

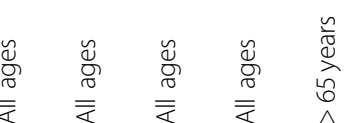

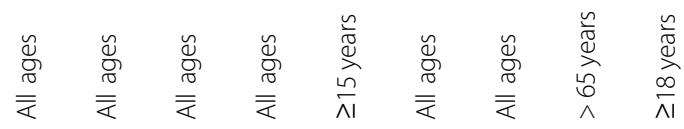

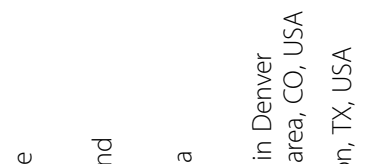

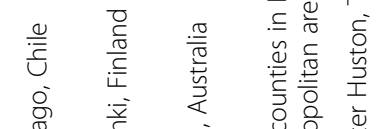

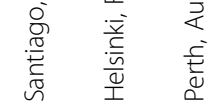

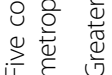

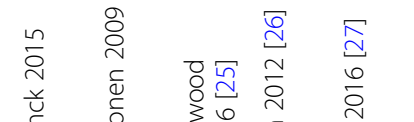

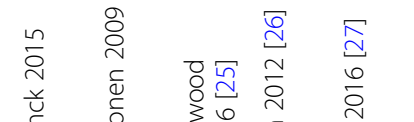

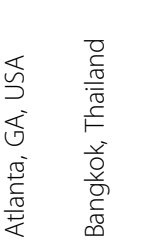

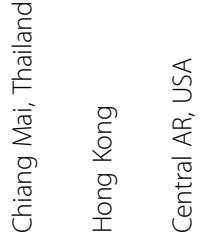

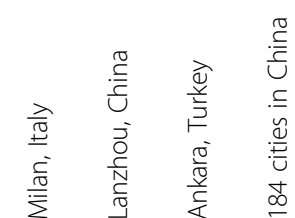

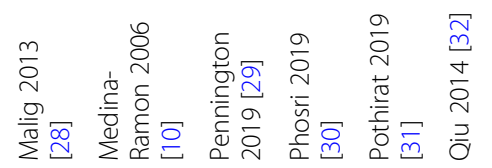

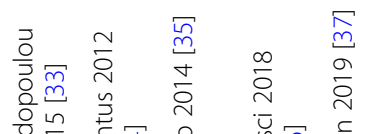




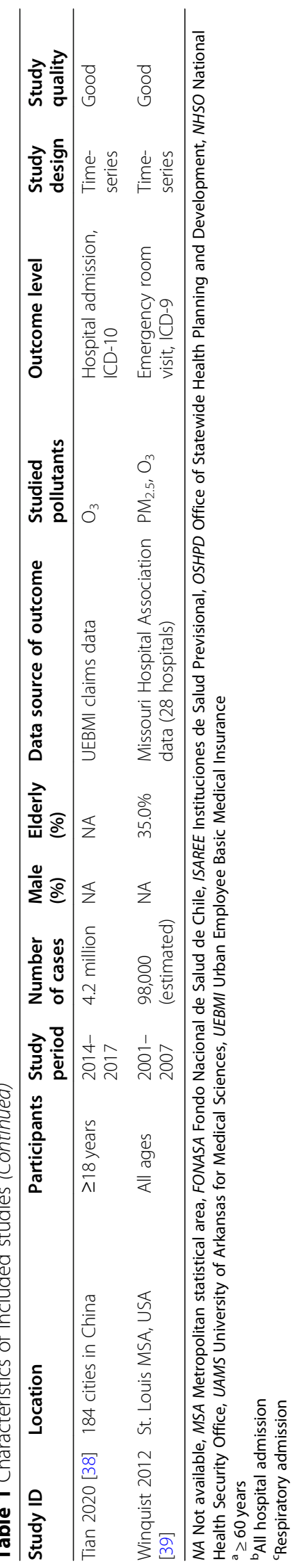




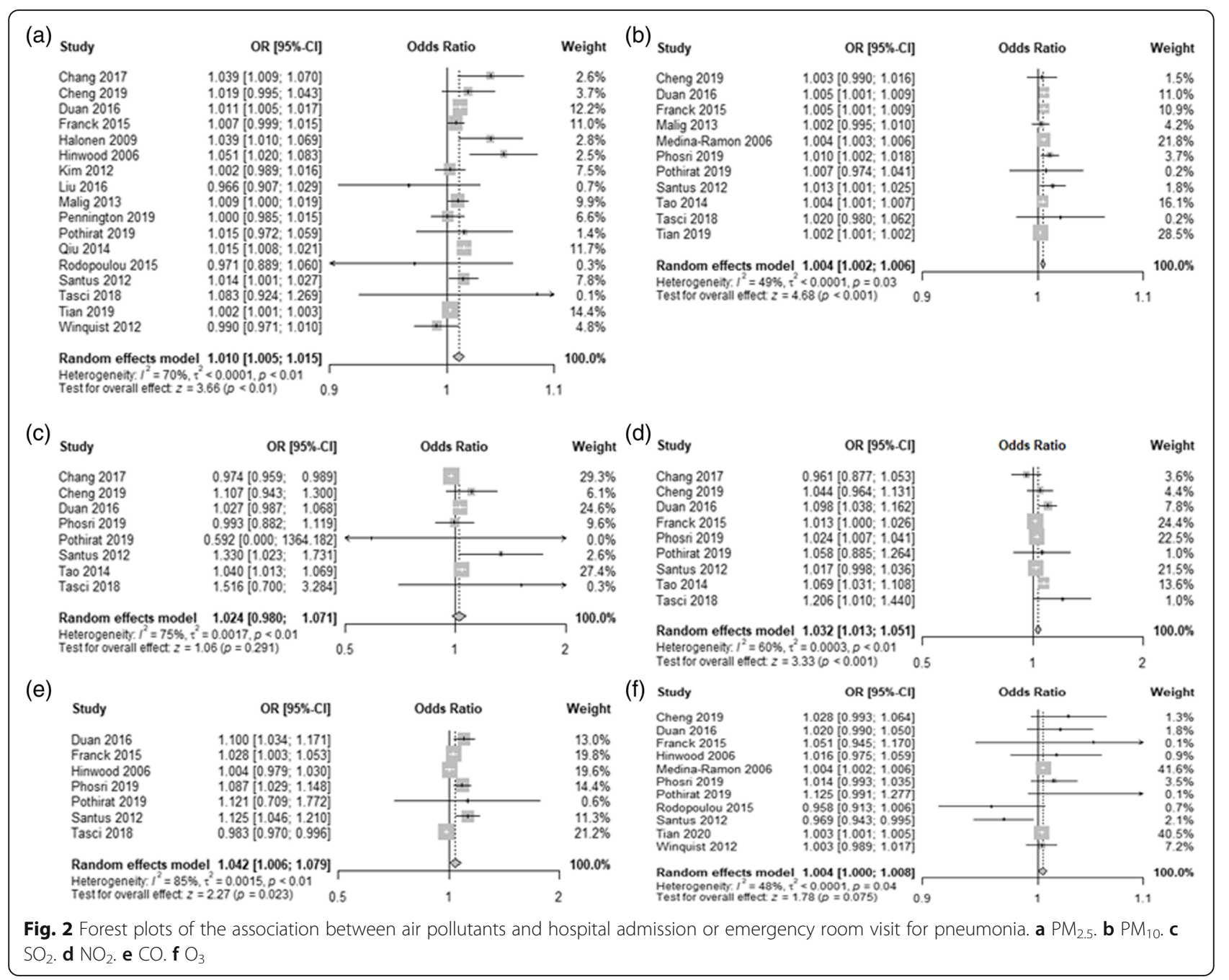

performed by sequentially excluding each study. With the exception of $\mathrm{CO}$, all pollutants, which obtained statistical significance in the main analyses, showed similar results, indicating that no individual study significantly affected the pooled results. The ranges of increase were $0.9-1.1 \%$ for $\mathrm{PM}_{2.5}, 0.4-0.5 \%$ for $\mathrm{PM}_{10}$, and $2.4-4.0 \%$ for $\mathrm{NO}_{2}$. When excluding the three largest studies, which had more than 1 million cases [10,37, 38], the pooled \% increase of hospital admission or ER visit per $10 \mu \mathrm{g} / \mathrm{m}^{3}$ increase in $\mathrm{PM}_{2.5}$ and $\mathrm{PM}_{10}$ and $10 \mathrm{ppb}$ in $\mathrm{O}_{3}$ was $1.1 \%$ (95\% CI: $0.6-1.6 ; \mathrm{I}^{2}=46.5 \%$ ), $0.5 \%$ (95\% CI: $0.3-0.7$; $\left.\mathrm{I}^{2}=0 \%\right)$, and $5.5 \% \quad\left(95 \%\right.$ CI: $\left.-1.1-2.2 ; \quad \mathrm{I}^{2}=56 \%\right)$, respectively.

As there were six and five studies for $\mathrm{PM}_{2.5}$ conducted in North America and East Asia, respectively, we performed a subgroup analysis. Analysis on East Asia showed that every $10 \mu \mathrm{g} / \mathrm{m}^{3}$ increase of $\mathrm{PM}_{2.5}$ was associated with a $1.2 \%$ (95\% CI: 0.3-2.0) increase in hospital admission or ER visit for pneumonia, whereas the effect estimate for North America was considerably smaller than that for East Asia; yet the confidence intervals still exhibited considerable overlap (0.3, 95\% CI: - 0.4-1.0). For $\mathrm{PM}_{10}$, East Asia and North America showed a 0.3\% (95\% CI: $0.1-0.4$ ) and 0.4\% (95\% CI: 0.3-0.6) increase for every $10 \mu \mathrm{g} / \mathrm{m}^{3}$ increase, respectively; for $\mathrm{O}_{3}$, the corresponding values were $0.9 \%(95 \% \mathrm{CI}:-0.5-2.4)$ and $0.2 \%$ (95\% CI: $-0.8-1.2)$. In terms of $\mathrm{SO}_{2}, \mathrm{NO}_{2}$ and $\mathrm{CO}$, there were no available studies conducted on North America.

When combining results with the same lag day, $\mathrm{PM}_{2.5}$ and $\mathrm{PM}_{10}$ showed significant associations with pneumonia-specific hospital admission or ER visit for all lag days (lag 0 to lag 5 ) and the largest association was observed for lag 3 and lag 5, respectively (See Supplementary Table 2 , Additional file 1 ). The $\%$ increase range per $10 \mu \mathrm{g} / \mathrm{m}^{3}$ increase for $\mathrm{PM}_{2.5}$ at lag 3 and $\mathrm{PM}_{10}$ at lag 5 was $1.0 \%$ (95\% CI: $0.4-1.6)$ and $0.4 \%$ (95\% CI: $0.2-$ $0.6)$, respectively. For $\mathrm{NO}_{2}$ and $\mathrm{CO}$, the largest association was observed for lag 2 (\% increase: 2.1, 95\% CI: $0.1-4.2$ ) and lag 5 (\% increase: 29.8, 95\% CI: 0.8-67.2), 
respectively. On the contrary, $\mathrm{SO}_{2}$ and $\mathrm{O}_{3}$ levels did not show significant associations for all lag days (lag 0 to lag5), and the \% increase range for $\mathrm{SO}_{2}$ and $\mathrm{O}_{3}$ was -0.3 to 1.9 and -1.0 to 0.7 , respectively.

\section{Discussion}

In this meta-analysis, we demonstrated a significant association between air pollutants $\left(\mathrm{PM}_{2.5}, \mathrm{PM}_{10}, \mathrm{NO}_{2}\right.$, and $\mathrm{CO}$ ) and hospital admission or ER visit for pneumonia, although no such association was identified regarding $\mathrm{SO}_{2}$ and $\mathrm{O}_{3}$. Except for $\mathrm{CO}$, the sensitivity analyses yielded similar results, demonstrating the robustness of the results. In a subgroup analysis by region, $\mathrm{PM}_{2.5}$ increased hospital admission or ER visit for pneumonia in East Asia but not in North America.

PM has been associated with cardiovascular hospitalization in several meta-analysis studies [8, 40]. $\mathrm{PM}_{2.5}$ was reported to even increase cardiovascular mortality by approximately 0.4 to $1.0 \%$ for every $10 \mu \mathrm{g} / \mathrm{m}^{3}$ [41]. Associations have also been reported between PM and other respiratory diseases, including asthma and COPD $[13,14]$. It was shown that asthmaand COPD-specific hospital admission increased by almost $2 \%$ for every $10 \mu \mathrm{g} / \mathrm{m}^{3}$ increase in $\mathrm{PM}_{2.5}$. Our findings are also consistent with a recent metaanalysis on short-term PM and pneumonia in children, which used similar meta-analytic methods, including time-series and case-crossover studies, and according to Nhung et al., a $10 \mu \mathrm{g} / \mathrm{m}^{3}$ increment of $\mathrm{PM}_{2.5}$ and $\mathrm{PM}_{10}$ was associated with a 1.8 and $1.5 \%$ increase in pneumonia hospital admission, respectively [42]. The higher estimates in children compared to our results may be attributed to their increased inhalation per body weight and immature immune systems, rendering them more susceptible to infections [43, 44].

Several studies have suggested that PM is related to inflammation. According to Gordon et al, $\mathrm{PM}_{2.5}$ is linked to an increase in pro-inflammatory cytokines (interleukin-1, interleukin-6, and tumor necrosis factor- $\alpha$ ) and Th1-type cytokines (interleukin-12 and interferon- $\gamma$ ) [45]. Elevated levels of white blood cells, C-reactive protein, and von Willebrand factor, which are involved in systemic inflammation, have also been observed after PM exposure [46, 47].

There are two possible mechanisms that mainly account for the increased risk of pneumonia induced by PM: altered immunity and oxidative stress, both of which are closely linked to inflammation. The respiratory system possesses multiple tiers of immunity to defend against harmful airborne particles and microorganisms [48]. However, despite its complex protective mechanisms, several studies have shown that $\mathrm{PM}_{2.5}$ exposure can damage the mucociliary system [49], suppress alveolar macrophage uptake [50], and impair microbial clearance [51], whereby it can enhance pneumococcal adherence to airway epithelial cells [52]. Although $\mathrm{PM}_{2.5}$, which can be inhaled more deeply into the lungs, is considered more harmful to health than $\mathrm{PM}_{10}$, the latter can also cause pneumonia in a similar manner [41].

Oxidative stress is another factor believed to play an important role in the pathogenesis of PM-induced pneumonia. Several studies have shown that acute exposure to PM triggers pulmonary oxidative stress. PM can directly generate reactive oxygen species on the surface, alter mitochondrial function, dysregulate antioxidant enzymes (e.g., superoxide dismutase), increase other oxidases in the lungs (e.g., inducible nitric oxide synthase), and activate metabolic enzyme activity including cytochrome P450s and glutathione S-transferase [53, 54]. These responses can cause pulmonary oxidative damage, which induces an inflammatory process in the lungs [55].

Along with $\mathrm{PM}, \mathrm{NO}_{2}$, a free-radical gaseous component of indoor and outdoor air pollution, was associated with increased risk of pneumonia hospital admission or ER visit in this study. As $\mathrm{NO}_{2}$ is linked to nitrosative stress in the lungs, it can lead to airway injury [56]. Furthermore, animal studies have shown that exposure to $\mathrm{NO}_{2}$ results in increased susceptibility to both bacterial and viral infections $[57,58]$, which explains the positive association between $\mathrm{NO}_{2}$ and pneumonia.

$\mathrm{CO}$ was another air pollutant associated with pneumonia. According to Ghio et al., CO can trigger proinflammatory responses in the airways [59]. In addition, previous studies have reported the association between $\mathrm{CO}$ and other respiratory diseases, including asthma and COPD $[13,60,61]$. However, in the sensitivity analysis, the association did not remain significant, especially when studies of Duan et al. [9], Phosri et al. [30], and Santus et al. [34] were excluded separately, possibly because the studies showed strong associations between $\mathrm{CO}$ and pneumonia in addition to having considerable weight. Therefore, caution is required to interpret the association between $\mathrm{CO}$ and pneumonia-specific hospital admission or ER visit.

Subgroup analysis by region showed that an increase of $\mathrm{PM}_{2.5}$ was associated with risk of hospital admission or ER visit for pneumonia in East Asia but not in North America. The two regions are known to have remarkably different concentrations of $\mathrm{PM}_{2.5}$ with East Asia generally having a higher exposure to $\mathrm{PM}_{2.5}$ and its consequent health burden than North America [62]. In addition, regional differences could be accounted for by the variability in composition and toxicity of air pollutants and/or variations in population susceptibility. As there have been insufficient studies investigating the direct effects of $\mathrm{PM}_{2.5}$ on pneumonia in different countries, further research is required on the effects of air pollutants between different regions. 
We performed meta-regression with the confounderadjusting method, which is assessed on a 0 to 3 scale by the third component of quality assessment (described in the method section). Except for $\mathrm{PM}_{10}$, no association between air pollutants and pneumonia was affected by the confounder-adjusting method. Although meta-regression analysis showed that the confounder-adjusting method affected the pooled estimates for $\mathrm{PM}_{10}$, most studies on $\mathrm{PM}_{10}$ yielded the same score (2 point); therefore, the result was not confirmative.

This meta-analysis has some limitations that should be considered when interpreting the results. First, included studies used the air pollutant levels obtained from monitoring stations rather than personal exposures. Second, considerable heterogeneity was observed. Third, due to the lack of information from individual studies, some potential factors, which could affect the risk of pneumonia-specific hospital admission or ER visit (e.g., patients' age or comorbidities), could not be adjusted.

\section{Conclusions}

To our knowledge, this is the first systematic review and meta-analysis to evaluate the acute effects of air pollutants on hospital admission or ER visit for pneumonia. By combining the inconsistent findings of several studies, this study revealed the associations between short-term exposure of air pollutants and pneumonia-specific hospital admission or ER visit, especially for $\mathrm{PM}$ and $\mathrm{NO}_{2}$. Based on the results, stricter intervention policies regarding air pollution and programs for protecting human respiratory health should be implemented.

\section{Supplementary Information}

The online version contains supplementary material available at https://doi. org/10.1186/s12940-020-00687-7.

\section{Additional file 1: Supplementary Table 1. Search strategy.}

Supplementary Table 2. Meta-analyses of association between air pollutants and hospital admission or emergency room visit for pneumonia in the same lag day. Supplementary Figure 1. Funnel plot of association between air pollutants and hospital admission or emergency room visit for pneumonia. a. Funnel plot of association between $\mathrm{PM}_{2.5}$ and hospital admission or emergency room visit for pneumonia. b. Funnel plot of association between $\mathrm{PM}_{10}$ and hospital admission or emergency room visit for pneumonia. c. Funnel plot of association between $\mathrm{SO}_{2}$ and hospital admission or emergency room visit for pneumonia. D. funnel plot of association between $\mathrm{NO}_{2}$ and hospital admission or emergency room visit for pneumonia. e. Funnel plot of association between $\mathrm{CO}$ and hospital admission or emergency room visit for pneumonia. f. Funnel plot of association between $\mathrm{O}_{3}$ and hospital admission or emergency room visit for pneumonia. Supplementary Figure 2. Subgroup analysis by region for the association between air pollutants and hospital admission or emergency room visit for pneumonia. a. Subgroup analysis by region for the association between $\mathrm{PM}_{2.5}$ and hospital admission or emergency room visit for pneumonia. b. Subgroup analysis by region for the association between $\mathrm{PM}_{10}$ and hospital admission or emergency room visit for pneumonia. c. Subgroup analysis by region for the association between $\mathrm{O}_{3}$ and hospital admission or emergency room visit for pneumonia. Supplementary Figure 3. Subgroup analysis by study design for the association between air pollutants and hospital admission or emergency room visit for pneumonia. a. Subgroup analysis by study design for the association between $\mathrm{PM}_{2.5}$ and hospital admission or emergency room visit for pneumonia. b. Subgroup analysis by study design for the association between $\mathrm{PM}_{10}$ and hospital admission or emergency room visit for pneumonia. c. Subgroup analysis by study design for the association between $\mathrm{SO}_{2}$ and hospital admission or emergency room visit for pneumonia. d. Subgroup analysis by study design for the association between $\mathrm{NO}_{2}$ and hospital admission or emergency room visit for pneumonia. e. Subgroup analysis by study design for the association between $\mathrm{CO}$ and hospital admission or emergency room visit for pneumonia. f. Subgroup analysis by study design for the association between $\mathrm{O}_{3}$ and hospital admission or emergency room visit for pneumonia. Supplementary Figure 4. Subgroup analysis by study quality for the association between air pollutants and hospital admission or emergency room visit for pneumonia. a. Subgroup analysis by study quality for the association between $\mathrm{PM}_{2.5}$ and hospital admission or emergency room visit for pneumonia. b. Subgroup analysis by study quality for the association between $\mathrm{PM}_{10}$ and hospital admission or emergency room visit for pneumonia. c. Subgroup analysis by study quality for the association between $\mathrm{SO}_{2}$ and hospital admission or emergency room visit for pneumonia. d. Subgroup analysis by study quality for the association between $\mathrm{NO}_{2}$ and hospital admission or emergency room visit for pneumonia. e. Subgroup analysis by study quality for the association between $\mathrm{CO}$ and hospital admission or emergency room visit for pneumonia. f. Subgroup analysis by study quality for the association between $\mathrm{O}_{3}$ and hospital admission or emergency room visit for pneumonia.

\section{Abbreviations}

Cls: Confidence intervals; COPD: Chronic obstructive pulmonary disease; ER: Emergency room; ICD: International Classification of Diseases; ORs: Odds ratios; PM: Particulate matter; PRISMA: Preferred Reporting Items for Systematic Reviews and Meta-analysis; WHO: World Health Organization

\section{Acknowledgements}

None.

\section{Authors' contributions}

YAC contributed to the acquisition of data, analysis, interpretation of data, and drafting the article. JY, YAC, HJY, and HY contributed to the interpretation of data. JY and HG contributed to the conception and design of the study, interpretation of data, and drafting and revising the article. All authors read and approved the final manuscript.

\section{Funding}

None.

Availability of data and materials

The datasets used and/or analysed during the current study are available from the corresponding author on reasonable request.

Ethics approval and consent to participate Not applicable.

Consent for publication

Not applicable.

\section{Competing interests}

The authors declare that they have no competing interests.

\section{Author details}

${ }^{1}$ College of Pharmacy and Graduate School of Pharmaceutical Sciences, Ewha Womans University, 52 Ewhayeodae-gil, Seodaemun-gu, Seoul 03760, Republic of Korea. ${ }^{2}$ College of Pharmacy, Gyeongsang National University, Jinju, Gyeongnam 52828, Republic of Korea. ${ }^{3}$ Mokhwa Convalescent Hospital, Jinju, Gyeongnam 52828, Republic of Korea. ${ }^{4}$ Department of Pharmacy, National Medical Center, Seoul 04564, Republic of Korea. ${ }^{5}$ Graduate School of Clinical Biohealth, Ewha Womans University, Seoul 03760, Republic of Korea. 
Received: 14 July 2020 Accepted: 14 December 2020 Published online: 07 January 2021

\section{References}

1. GBD 2016 Lower Respiratory Infections Collaborators. Estimates of the global, regional, and national morbidity, mortality, and aetiologies of lower respiratory infections in 195 countries, 1990-2016: a systematic analysis for the Global Burden of Disease Study 2016. Lancet Infect Dis. 2018;18:1191-210.

2. Wunderink RG, Waterer GW. Clinical practice. Community-acquired pneumonia. N Engl J Med. 2014;370:543-51.

3. Jain S, Self WH, Wunderink RG, Fakhran S, Balk R, Bramley AM, et al. Community-acquired pneumonia requiring hospitalization among U.S. adults. N Engl J Med. 2015;373:415-27.

4. World Health Organization. Ambient (outdoor) air pollution: World Health Organization; 2020. https://www.who.int/news-room/fact-sheets/detail/ ambient-(outdoor)-air-quality-and-health. Accessed 9 June 2020.

5. World Health Organization. Ambient air pollution: a global assessment of exposure and burden of disease: World Health Organization; 2016. https:// apps.who.int/iris/handle/10665/250141. Accessed 9 June 2020.

6. Anderson JO, Thundiyil JG, Stolbach A. Clearing the air: a review of the effects of particulate matter air pollution on human health. J Med Toxicol. 2012:8:166-75

7. Hoek G, Krishnan RM, Beelen R, Peters A, Ostro B, Brunekreef B, et al. Long term air pollution exposure and cardio- respiratory mortality: a review. Environ Health. 2013;12:43.

8. Brook RD, Rajagopalan S, Pope CA 3rd, Brook JR, Bhatnagar A, Diez-Roux AV et al. Particulate matter air pollution and cardiovascular disease: an update to the scientific statement from the American Heart Association. Circulation. 2010;121:2331-78.

9. Duan Z, Han X, Bai Z, Yuan Y. Fine particulate air pollution and hospitalization for pneumonia: a case-crossover study in Shijiazhuang, China. Air Qual Atmos Health. 2016;9:723-33.

10. Medina-Ramón M, Zanobetti A, Schwartz J. The effect of ozone and PM10 on hospital admissions for pneumonia and chronic obstructive pulmonary disease: a national multicity study. Am J Epidemiol. 2006;163:579-88.

11. Li R, Jiang N, Liu Q, Huang J, Guo X, Liu F, et al. Impact of air pollutants on outpatient visits for acute respiratory outcomes. Int J Environ Res Public Health. 2017;14:47

12. Chen CC, Huang JB, Cheng SY, Wu KH, Cheng FJ. Association between particulate matter exposure and short-term prognosis in patients with pneumonia. Aerosol Air Qual Res. 2020;20:89-96.

13. Zheng XY, Ding H, Jiang LN, Chen SW, Zheng JP, Qiu M, et al. Association between air pollutants and asthma emergency room visits and hospital admissions in time series studies: a systematic review and meta-analysis. PLoS One. 2015;10:e0138146

14. Zhu RX, Nie XH, Chen YH, Chen J, Wu SW, Zhao LH. Relationship between particulate matter (PM2.5) and hospitalizations and mortality of chronic obstructive pulmonary disease patients: A meta-analysis. Am J Med Sci. 2020;359:354-64.

15. Atkinson RW, Kang S, Anderson HR, Mills IC, Walton HA. Epidemiological time series studies of PM2.5 and daily mortality and hospital admissions: a systematic review and meta-analysis. Thorax. 2014;69:660-5.

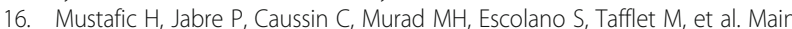
air pollutants and myocardial infarction: a systematic review and metaanalysis. JAMA. 2012;307:713-21.

17. Shah AS, Langrish JP, Nair H, McAllister DA, Hunter AL, Donaldson K, et al. Global association of air pollution and heart failure: a systematic review and meta-analysis. Lancet. 2013;382:1039-48.

18. DerSimonian R, Laird N. Meta-analysis in clinical trials. Control Clin Trials. 1986;7:177-88

19. Begg CB, Mazumdar M. Operating characteristics of a rank correlation test for publication bias. Biometrics. 1994;50:1088-101.

20. Moher D, Liberati A, Tetzlaff J, Altman DG, PRISMA Group. Preferred reporting items for systematic reviews and meta-analyses: the PRISMA statement. PLoS Med. 2009;6:e1000097.

21. Chang JH, Hsu SC, Bai KJ, Huang SK, Hsu CW. Association of time-seria changes in ambient particulate matters (PMs) with respiratory emergency cases in Taipei's Wenshan District. PLoS One. 2017;12:e0181106.

22. Cheng FJ, Lee KH, Lee CW, Hsu PC. Association between particulate matter air pollution and hospital emergency room visits for pneumonia with septicemia: a retrospective analysis. Aerosol Air Qual Res. 2019;19:345-54.
23. Franck U, Leitte AM, Suppan P. Multifactorial airborne exposures and respiratory hospital admissions--the example of Santiago de Chile. Sci Total Environ. 2015;502:114-21.

24. Halonen Jl, Lanki T, Yli-Tuomi T, Tiittanen P, Kulmala M, Pekkanen J. Particulate air pollution and acute cardiorespiratory hospital admissions and mortality among the elderly. Epidemiology. 2009;20:143-53.

25. Hinwood AL, De Klerk N, Rodriguez C, Jacoby $P$, Runnion T, Rye $P$, et al. The relationship between changes in daily air pollution and hospitalizations in Perth, Australia 1992-1998: a case-crossover study. Int J Environ Health Res. 2006;16:27-46

26. Kim SY, Peel JL, Hannigan MP, Dutton SJ, Sheppard L, Clark ML, et al. The temporal lag structure of short-term associations of fine particulate matter chemical constituents and cardiovascular and respiratory hospitalizations. Environ Health Perspect. 2012;120:1094-9.

27. Liu S, Ganduglia CM, Li X, Delclos GL, Franzini L, Zhang K. Short-term associations of fine particulate matter components and emergency hospital admissions among a privately insured population in greater Houston. Atmos Environ. 2016;147:369-75.

28. Malig BJ, Green S, Basu R, Broadwin R. Coarse particles and respiratory emergency department visits in California. Am J Epidemiol. 2013;178:58-69.

29. Pennington AF, Strickland MJ, Gass K, Klein M, Sarnat SE, Tolbert PE, et al. Source-Apportioned PM2.5 and Cardiorespiratory Emergency Department Visits: Accounting for Source Contribution Uncertainty. Epidemiology. 2019; 30:789-98.

30. Phosri A, Ueda K, Phung VLH, Tawatsupa B, Honda A, Takano H. Effects of ambient air pollution on daily hospital admissions for respiratory and cardiovascular diseases in Bangkok, Thailand. Sci Total Environ. 2019;651: $1144-53$

31. Pothirat C, Chaiwong W, Liwsrisakun C, Bumroongkit C, Deesomchok A, Theerakittikul T, et al. Acute effects of air pollutants on daily mortality and hospitalizations due to cardiovascular and respiratory diseases. J Thorac Dis. 2019;11:3070-83.

32. Qiu H, Tian LW, Pun VC, Ho KF, Wong TW, Yu IT. Coarse particulate matter associated with increased risk of emergency hospital admissions for pneumonia in Hong Kong. Thorax. 2014;69:1027-3.

33. Rodopoulou S, Samoli E, Chalbot MG, Kavouras IG. Air pollution and cardiovascular and respiratory emergency visits in Central Arkansas: a timeseries analysis. Sci Total Environ. 2015;536:872-9.

34. Santus P, Russo A, Madonini E, Allegra L, Blasi F, Centanni S, et al. How air pollution influences clinical management of respiratory diseases. A casecrossover study in Milan. Respir Res. 2012;13:95.

35. Tao Y, Mi S, Zhou S, Wang S, Xie X. Air pollution and hospital admissions for respiratory diseases in Lanzhou, China. Environ Pollut. 2014;185:196-201.

36. Tasci SS, Kavalci C, Kayipmaz AE. Relationship of meteorological and air pollution parameters with pneumonia in elderly patients. Emerg Med Int. 2018;2018:4183203.

37. Tian Y, Liu H, Wu Y, Si Y, Li M, Wu Y, et al. Ambient particulate matter pollution and adult hospital admissions for pneumonia in urban China: a national time series analysis for 2014 through 2017. PLoS Med. 2019;16: e1003010.

38. Tian $Y$, Wu Y, Liu H, Si Y, Wu Y, Wang $X$, et al. The impact of ambient ozone pollution on pneumonia: a nationwide time-series analysis. Environ Int. 2020:136:105498.

39. Winquist A, Klein M, Tolbert P, Flanders WD, Hess J, Sarnat SE. Comparison of emergency department and hospital admissions data for air pollution time-series studies. Environ Health. 2012;11:70.

40. Adar SD, Filigrana PA, Clements N, Peel JL. Ambient coarse particulate matter and human health: a systematic review and meta-analysis. Curr Environ Health Rep. 2014;1:258-74.

41. Pope CA 3rd, Dockery DW. Health effects of fine particulate air pollution: lines that connect. J Air Waste Manag Assoc. 2006;56:709-42.

42. Nhung NTT, Amini H, Schindler C, Kutlar Joss M, Dien TM, Probst-Hensch N, et al. Short-term association between ambient air pollution and pneumonia in children: a systematic review and meta-analysis of time-series and casecrossover studies. Environ Pollut. 2017;230:1000-8.

43. Posfay-Barbe KM, Zerr DM, Pittet D. Infection control in paediatrics. Lancet Infect Dis. 2008:8:19-31.

44. Makri A, Stilianakis NI. Vulnerability to air pollution health effects. Int J Hyg Environ Health. 2008;211:326-36.

45. Gordon S. Alternative activation of macrophages. Nat Rev Immunol. 2003; $3(1): 23-35$. 
46. Hassanvand MS, Naddafi K, Kashani H, Faridi S, Kunzli N, Nabizadeh R, et al. Short-term effects of particle size fractions on circulating biomarkers of inflammation in a panel of elderly subjects and healthy young adults. Environ Pollut. 2017;223:695-704

47. Li W, Dorans KS, Wilker EH, Rice MB, Ljungman PL, Schwartz JD, et al. Shortterm exposure to ambient air pollution and biomarkers of systemic inflammation: the Framingham heart study. Arterioscler Thromb Vasc Biol. 2017;37:1793-800.

48. Iwasaki A, Foxman EF, Molony RD. Early local immune defences in the respiratory tract. Nat Rev Immunol. 2017;17:7-20.

49. Ferreira-Ceccato AD, Ramos EM, de Carvalho LC Jr, Xavier RF, Teixeira MF, Raymundo-Pereira PA, et al. Short-term effects of air pollution from biomass burning in mucociliary clearance of Brazilian sugarcane cutters. Respir Med. 2011;105:1766-8.

50. Clarke RW, Antonini JM, Hemenway DR, Frank R, Kleeberger SR, Jakab GJ. Inhaled particle-bound sulfate: effects on pulmonary inflammatory responses and alveolar macrophage function. Inhal Toxicol. 2000;12:169-86.

51. Phipps JC, Aronoff DM, Curtis JL, Goel D, O'Brien E, Mancuso P. Cigarette smoke exposure impairs pulmonary bacterial clearance and alveolar macrophage complement-mediated phagocytosis of Streptococcus pneumoniae. Infect Immun. 2010;78:1214-20.

52. Mushtaq N, Ezzati M, Hall L, Dickson I, Kirwan M, Png KM, et al. Adhesion of Streptococcus pneumoniae to human airway epithelial cells exposed to urban particulate matter. J Allergy Clin Immunol. 2011;127:1236-42.

53. Risom L, Møller P, Loft S. Oxidative stress-induced DNA damage by particulate air pollution. Mutat Res. 2005:592:119-37.

54. Li R, Kou X, Xie L, Cheng F, Geng H. Effects of ambient PM2.5 on pathological injury, inflammation, oxidative stress, metabolic enzyme activity, and expression of c-fos and c-Jun in lungs of rats. Environ Sci Pollut Res Int. 2015;22:20167-76.

55. Riva DR, Magalhães CB, Lopes AA, Lanças T, Mauad T, Malm O, et al. Low dose of fine particulate matter (PM2.5) can induce acute oxidative stress, inflammation and pulmonary impairment in healthy mice. Inhal Toxicol. 2011;23:57-67.

56. Marozkina NV, Gaston B. Nitrogen chemistry and lung physiology. Annu Rev Physiol. 2015;77:431-52.

57. Chauhan AJ, Johnston SL. Air pollution and infection in respiratory illness. Br Med Bull. 2003;68:95-112.

58. Rose RM, Pinkston P, Skornik WA. Altered susceptibility to viral respiratory infection during short-term exposure to nitrogen dioxide. Res Rep Health Eff Inst. 1989;24:1-24

59. Ghio AJ, Smith CB, Madden MC. Diesel exhaust particles and airway inflammation. Curr Opin Pulm Med. 2012;18:144-50.

60. Sunyer J, Antó JM, Murillo C, Saez M. Effects of urban air pollution on emergency room admissions for chronic obstructive pulmonary disease. Am J Epidemiol. 1991;134:277-86.

61. Li J, Sun S, Tang R, Qiu H, Huang Q, Mason TG, et al. Major air pollutants and risk of COPD exacerbations: a systematic review and meta-analysis. Int J Chron Obstruct Pulmon Dis. 2016;11:3079-91.

62. Cohen AJ, Brauer M, Burnett R, Anderson HR, Frostad J, Estep K, et al. Estimates and 25-year trends of the global burden of disease attributable to ambient air pollution: an analysis of data from the global burden of diseases study 2015. Lancet. 2017;389:1907-18.

\section{Publisher's Note}

Springer Nature remains neutral with regard to jurisdictional claims in published maps and institutional affiliations.

Ready to submit your research? Choose BMC and benefit from:

- fast, convenient online submission

- thorough peer review by experienced researchers in your field

- rapid publication on acceptance

- support for research data, including large and complex data types

- gold Open Access which fosters wider collaboration and increased citations

- maximum visibility for your research: over $100 \mathrm{M}$ website views per year

At BMC, research is always in progress.

Learn more biomedcentral.com/submissions 